\title{
Maximizing Productivity of Greenhouse-grown Hydroponic Lettuce during Winter
}

\author{
Alexander Miller, Petrus Langenhoven, and Krishna Nemali \\ Department of Horticulture and Landscape Architecture, Purdue University, \\ 625 Agriculture Mall Drive, West Lafayette, IN 47907
}

Additional index words. controlled environment agriculture, cold tolerance, leafy greens, light quality

\begin{abstract}
Operational cost of producing lettuce (Lactuca sativa) during the winter in greenhouses is high in the northern regions of the United States due to the addition of supplemental lighting (SL) and heating. Crop productivity in greenhouses should increase to offset high operational costs and maintain profits. Factors including SL composition, heating efficiency, suitability of production systems (PS), and cultivar performance can affect crop productivity. Research-based information on optimizing the above environmental- and production-related factors is limited. This information is critical for growers to make informed decisions and increase profits during winter hydroponic production. We evaluated the interactive effects of SL composition, solution temperature, PS, and cultivar treatments on lettuce shoot dry weight (SDW, $g \cdot \mathbf{m}^{-2}$ ) and shoot water content (SWC, \%) in a greenhouse maintained at suboptimal air temperature $\left(13.7^{\circ} \mathrm{C}\right)$ using a split-plot design. There were three light treatments (sunlight without SL, sunlight + narrow-spectrum SL at nighttime, and sunlight + full-spectrum SL at nighttime), two solution temperature levels [heated $\left(18.8^{\circ} \mathrm{C}\right)$ and unheated $\left(13.2{ }^{\circ} \mathrm{C}\right)$ ], two hydroponic PS [constant flood technique (CFT) and nutrient film technique (NFT)], and eight cultivars included in the study. Results indicated that 1) a narrow-spectrum SL at nighttime in combination with heated solution resulted in maximum SDW of lettuce, 2) the SDW and SWC (major determinant of economic yield) increase between the heated and unheated solution temperature treatments was higher in the CFT than in the NFT, and 3) the positive effects of using heated solution were seen mainly in the green-color cultivars. Our research identified the optimal spectral composition of nighttime SL, tested the positive effects of alternate heating methods using heated solution on plant growth under suboptimal air temperature conditions, compared the suitability of two hydroponic PS for lettuce production, and quantified yield potential of several lettuce cultivars in hydroponic production during winter. Growers can use our research findings to make informed decisions about their investment and to maximize hydroponic lettuce productivity and profits during winter.
\end{abstract}

Hydroponics is a common method of growing crops in controlled environment agriculture systems (Jensen, 1999). Leafy greens like lettuce are a popular choice for hydroponic production (Curran, 2018). Lettuce can potentially fetch a higher price in winter than in other seasons due to decreased field acreage and production. However, maintaining an optimal environment for lettuce in a greenhouse can be challenging with prevailing light and temperature conditions during winter in the northern regions of the Unites States. Optimal light intensity for lettuce is 12 to $15 \mathrm{~mol} \cdot \mathrm{m}^{-2} \cdot \mathrm{d}^{-1}$ (Both et al., 1997; Kang et al., 2013; Zhang et al., 2018). The normal sunlight levels received inside a greenhouse are well below the optimal in the northern regions of the United States during winter (Korczynski et al., 2002). Although lettuce is a cool-season crop, the optimal temperature for lettuce is between 20 to $24{ }^{\circ} \mathrm{C}$ (Brechner and Both, 2013; Gent, 2016). The average outside temperature during winter in many northern regions of the United States is close to freezing (NCEI, 2020). Greenhouse temperature can only be able on these factors for growers to make informed decisions.

Light emitting diode (LED)-based SL are energy-efficient and highly durable (Nelson and Bugbee, 2014), making them an ideal choice for greenhouse lighting. Recently, Kong et al. (2019) surmised that lettuce yields could increase by $17 \%$ using optimal LED composition in indoor hydroponics. They further concluded that a red-to-blue ratio of 4.5 was optimal for several lettuce cultivars in indoor production. The SL composition provided during the daytime may have a smaller effect on lettuce yield compared with that observed in indoor production. This is because sunlight composition can mask the effects of SL composition provided during the daytime (Ouzounis et al., 2015). Research indicated that SL "intensity" provided at nighttime is as effective as that provided during the daytime in increasing crop growth (Tewolde et al., 2016). However, limited information is available on the effects of SL "composition" provided at nighttime on lettuce growth.

Compared with conventional greenhouse heating during winter, methods that supply heat directly to the roots can be more energy efficient. Root temperature affects plant morphology, respiration, transpiration, water movement, and nutrient uptake in lettuce (Gent, 2016). Gerovac and Lopez (2014) showed that heat supplied to the root zone, while maintaining lower-than-optimal air temperature, can maintain plant growth and reduce the energy costs of heating in bedding plant production. It is possible to increase the temperature of roots by recirculating heated nutrient solution in liquid-based hydroponic systems. Warmer temperature of the root zone likely increases the temperature of the air surrounding shoots, even when air temperature is suboptimal. Butterhead lettuce yields were comparable between air temperatures of 17 and $24{ }^{\circ} \mathrm{C}$ when water temperature was maintained at $24{ }^{\circ} \mathrm{C}$ (Thompson et al., 1998). However, the positive effects of supplying heated nutrient solution on shoot growth may depend on the proportion of roots exposed to the solution. The extent of roots in contact with nutrient solution can vary among different PS. For example, root contact with nutrient solution is partial in the NFT, whereas roots are completely submerged inside the solution in the CFT. Therefore, the positive effects of using a heated nutrient solution on lettuce growth may vary among different PS. However, studies that have compared the effect of heated hydroponic solution on crop growth in different PS are limited.

Using a suitable PS and fast-growing cultivar can increase productivity in greenhouse hydroponics. A study that compared NFT and deep-water culture (DWC) systems in aquaponics, found that lettuce yield was higher in DWC than NFT (Lennard and Leonard, 2006). In another study, spinach grown under NFT had a higher yield than DWC, but only in the summer (Ikeda et al., 1995). For basil, DWC produced a slightly 
higher yield than NFT, but differences were not significant (Walters and Currey, 2015). Thus, findings from research on the best production systems for leafy greens are variable and unclear. Lettuce cultivars have shown growth differences between hydroponics and substrate culture (Assimakopoulou et al., 2013). However, available information on the growth responses of lettuce cultivars to different hydroponic PS is limited. Further, the information on the effects of solution temperature and composition of nighttime SL on cultivar productivity is limited.

The purpose of our research was to develop research-based information on the environment (light and temperature) and production (type of production system and cultivar) -related factors (described above) so that greenhouse growers could make informed decisions about their investment. Our objective was to study the interactive effects of nighttime SL spectral composition, nutrient solution temperature, PS, and cultivar on lettuce productivity in a greenhouse maintained at the suboptimal conditions that are generally observed in the northern regions of the United States during winter.

\section{Materials and Methods}

Greenhouse environment. The study was conducted in a glass greenhouse during January and February of 2019. The average daily light integral (DLI) received from sunlight was $5.8( \pm 1.75) \mathrm{mol} \cdot \mathrm{m}^{-2} \cdot \mathrm{d}^{-1}$ during the study. The greenhouse was maintained at an average daytime (8:00 AM to 6:00 PM), nighttime, and 24-h period temperatures of $15.0( \pm 0.23)$,

Received for publication 17 Aug. 2020. Accepted for publication 21 Sept. 2020.

Published online 5 November 2020.

We thank the United States Department of Agriculture and the Indiana State Department of Agriculture for funding the research (Award Number 16-SCBGP-IN-0052).

This report was prepared as an account of work sponsored by an agency of the United States Government and the State of Indiana. Neither the United States Government nor State of Indiana, nor any agency thereof, nor any of their employees, makes any warranty, express or implied, or assumes any legal liability or responsibility for the accuracy, completeness, or usefulness of any information, apparatus, product, or process disclosed, or represents that its use would not infringe privately owned rights. Reference herein to any specific commercial product, process, or service by trade name, trademark, manufacturer, or otherwise does not necessarily constitute or imply its endorsement, recommendation, or favoring by the United States Government, the State of Indiana, or any agency thereof. The views and opinions of authors expressed herein do not necessarily state or reflect those of the United States Government, the State of Indiana, or any agency thereof.

K.N. is the corresponding author. E-mail: knemali@ purdue.edu.

This is an open access article distributed under the $\mathrm{CC}$ BY-NC-ND license (https://creativecommons.org/ licenses/by-nc-nd/4.0/).
$12.6( \pm 0.50)$, and $13.7( \pm 0.26){ }^{\circ} \mathrm{C}$, respectively. Relative humidity ( $\mathrm{RH}$ ) was not controlled but rather measured in the center of the greenhouse. The average RH during the study was $31.7( \pm 12.81) \%$.

Plant materials and sowing. We grew eight lettuce cultivars belonging to different groups and leaf colors (a full list in the Treatments section) in the study. Selected cultivars were best performers in each group from a previous variety trial. We purchased seeds from Paramount Seed Inc. (Stuart, FL) and Johnny's Selected Seed (Winslow, ME). Seeds were germinated in rockwool cubes (2.5- $\mathrm{cm}$ diameter; Grodan, Roermond, The Netherlands). Sheets containing 200 cubes each were placed on standard watertight trays $(54 \mathrm{~cm} \times 27 \mathrm{~cm} \times 3 \mathrm{~cm}$; Greenhouse Megastore, Danville, IL) filled with 1 liter of plain water. Water was added to the trays as needed during germination. Rockwool cubes absorbed water from the trays by capillarity and remained moist during the germination phase. We thinned and retained one seedling per cube after germination. A dilute nutrient solution with an electrical conductivity (EC) of 0.25 $\mathrm{dS} \cdot \mathrm{m}^{-1}$ (or $22 \mathrm{mg} \cdot \mathrm{L}^{-1} \mathrm{~N}$; see the Nutrient solution management section for details) was supplied to the seedlings as needed during the nursery stage. After ten days from sowing, we separated the rockwool cubes with seedlings from the sheets and placed them in hydroponic systems.

Hydroponic production systems. The CFT and NFT systems were custom-built on greenhouse benches $(7.62 \mathrm{~m} \times 1.5 \mathrm{~m} \times$ $1.1 \mathrm{~m}$ ) using reservoirs (76 L; Active Aqua Premium white reservoir; Petaluma, CA) and submersible pumps (530 LPH; Total Pond, West Palm Beach, FL).

We built the CFT system using flood tables $(122 \mathrm{~cm} \times 31 \mathrm{~cm} \times 10 \mathrm{~cm}$; Botanicare, Vancouver, WA) and plastic lids. An extension fitting ( $5 \mathrm{~cm}$; Botanicare) was inserted into the outlet end of the CFT tray to allow the flood of nutrient solution to accumulate to $\approx 5-\mathrm{cm}$ depth in the tray before draining. Holes (6-cm diameter) were made on the CFT lids to insert net pots $(5.1-\mathrm{cm}$ diameter; General Hydroponics, Chico, CA). Rockwool cubes with seedlings were placed inside the net pots. The flood of the nutrient solution passed through the net pots, but the rockwool cubes were held in position by the net pots. The NFT channels $(150 \mathrm{~cm} \times 12 \mathrm{~cm} \times 4 \mathrm{~cm})$ and covers with pre-made holes (3-cm diameter) were purchased from a vendor (Crop King Inc., Lodi, OH) and assembled in the study. The inlet side of the NFT channels was raised by $15 \mathrm{~cm}$, creating a $9.8 \%$ slope, for the nutrient solution to flow as a film toward the channel outlet. Rockwool cubes with seedlings were directly placed in the NFT system by inserting them through the square holes on the channel covers and making them have contact with the base of the channel.

A unit of PS consisted of two NFT channels or one CFT tray. The grow area of the CFT and NFT units was 0.38 and $0.36 \mathrm{~m}^{2}$, respectively. Each CFT and NFT unit supported 16 plants. This resulted in 42 and 44 plants $/ \mathrm{m}^{2}$ in the CFT and NFT systems, respectively. Each reservoir stored $\approx 40 \mathrm{~L}$ of the nutrient solution. Four PS units, including two NFT units (four channels) and two CFT trays, were connected to one reservoir. There were four pumps in each reservoir, one for each PS unit. A black-vinyl tubing (1.3-cm internal diameter; Crop King Inc.) was used to connect the pumps to PS and to drain the nutrient solution back to the reservoirs. Flow valves $(1.3 \mathrm{~cm}$, Green Back in-line valve; Botanicare) connected to the inlet tubing were used to control the rate of nutrient solution delivery to the CFT and NFT systems. The flowrate measured on the outlet end of the CFT and NFT systems was $\approx 6.0$ and $1.0 \mathrm{~L} \cdot \mathrm{min}^{-1}$, respectively.

Nutrient solution management. Watersoluble fertilizers containing $\mathrm{N}-\mathrm{P}-\mathrm{K}$ levels of 5.0-4.8-21.5 (5-11-26 Peters Professional; ICL Specialty Fertilizers, Summerville, SC) and 15.5-0-0 (calcium nitrate; YaraLiva, Yara, Tampa, FL) were mixed in a 1.8:1 ratio, respectively, to prepare the nutrient solution. Nitrogen in the solution was comprised of $96.5 \% \mathrm{NO}_{3}{ }^{-}$and $3.5 \%$ $\mathrm{NH}_{4}{ }^{+}$forms. A fertilizer injector (D14MZ2; Dosatron International, Clearwater, FL) was used to mix nutrient stock solution with water to the desired strength. About $440 \mathrm{~g}$ of composite fertilizer was mixed with $10 \mathrm{~L}$ of water to prepare the stock solution. Nutrient solution from the fertilizer injector was delivered to the reservoirs using a water hose. Reservoirs were filled with fresh nutrient solution on the first, seventh, 15th, 21st, 28th, and 32 nd day of the study. The EC of the nutrient solution supplied to the reservoirs on the first, seventh, and 15 th day was $0.5 \mathrm{dS} \cdot \mathrm{m}^{-1}$ (45 $\mathrm{mg} \cdot \mathrm{L}^{-1} \mathrm{~N}$, injector ratio of $\left.200: 1\right)$. It was 1.0 $\mathrm{dS} \cdot \mathrm{m}^{-1}\left(90 \mathrm{mg} \cdot \mathrm{L}^{-1} \mathrm{~N}\right.$, injector ratio of $\left.100: 1\right)$ on the $21 \mathrm{st}$ and $28 \mathrm{th}$ day and $1.7 \mathrm{dS} \cdot \mathrm{m}^{-1}(150$ $\mathrm{mg} \cdot \mathrm{L}^{-1} \mathrm{~N}$, injector ratio of $\left.60: 1\right)$ on the $32 \mathrm{nd}$ day of the study. The EC of the nutrient solution in the reservoirs was continuously measured using pre-calibrated dielectric sensors (5TE; Meter Group, Pullman, WA) connected to a datalogger (CR1000x; Campbell Scientific, Logan, UT). A handheld $\mathrm{pH}$ sensor (SI600; Spectrum Technologies, Aurora, IL) was used to regularly check the solution $\mathrm{pH}$ values. As the $\mathrm{pH}$ of irrigation water was $\approx 7.5$, a small volume ( 1 to $3 \mathrm{~mL}$ ) of sulfuric acid (85\%; ACCO Unlimited Corp., Johnston, IA) was added to the nutrient solution in the reservoirs as needed to maintain the $\mathrm{pH}$ between 5.5 and 6.5 .

Treatments. The study had these treatments: three light, two solution temperature, two PS, and eight cultivar. Light treatments included 1) sunlight with no SL (NSL), 2) sunlight with full-spectrum SL at nighttime (WSL), and 3) sunlight with narrowspectrum SL at nighttime (PSL). Supplemental lighting was provided using LED lights (Ray 44; Fluence Bioengineering, Austin, TX) with different spectra. Four LED bars of the same type were grouped together in each light treatment. Each LED light bar was $56 \mathrm{~cm}$ long, and the bars were spaced $46 \mathrm{~cm}$ apart. The height of light bars above the 


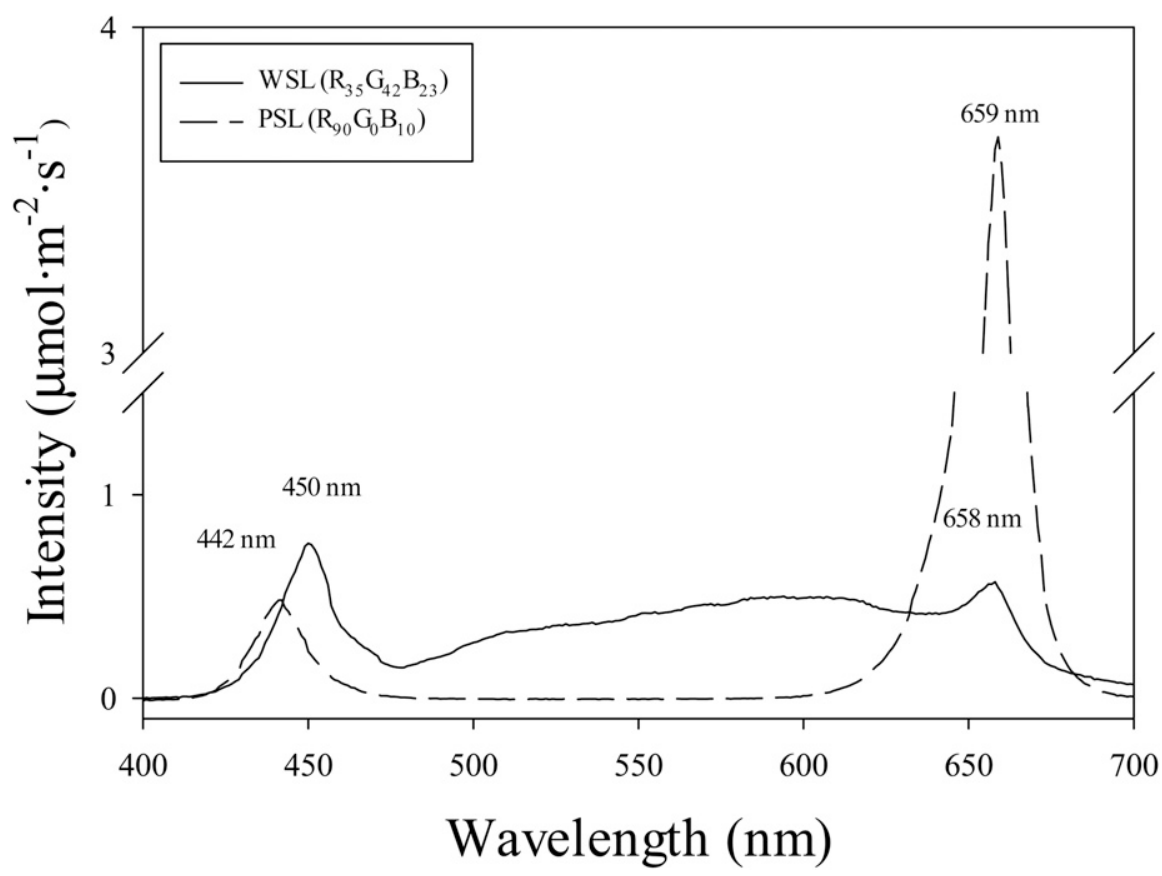

Fig. 1. Spectral composition of supplemental light provided to plants at nighttime in the study (PSL $=$ sunlight with narrow-spectrum supplemental light at nighttime, WSL = sunlight with full-spectrum supplemental light at nighttime). The subscripts of R, G, and B indicate percentages of red (600 to 700 $\mathrm{nm}$ ), green ( 500 to $599 \mathrm{~nm}$ ), and blue (400 to $499 \mathrm{~nm}$ ) wave bands, respectively. Numbers in the graph indicate peak wavelengths for blue and red wavebands in each treatment.

plants was minimally adjusted to maintain similar light intensity levels in different sections. The red $\left(R_{x}\right)$, green $\left(G_{y}\right)$, and blue $\left(B_{z}\right)$ percentages (i.e., $x, y$, and $z$ ) in the WSL and PSL treatments, as measured by a field spectroradiometer (model SS110; Apogee Instruments) at nighttime, were $\mathrm{R}_{35}: \mathrm{G}_{42}: \mathrm{B}_{23}$ and $R_{90}: G_{0}: B_{10}$, respectively (Fig. 1). The light composition of sunlight in the photosynthetically active range received inside the greenhouse on a cloud-free day was $\mathrm{R}_{35}: \mathrm{G}_{34}$ : $\mathrm{B}_{31}$. A quantum sensor (SQ110; Apogee Instruments, Logan, UT) connected to a datalogger (CR100X; Campbell Scientific) was placed at canopy height in the middle of each light treatment to continuously measure incident light intensity. Plants in the NSL, WSL, and PSL treatments received an average DLI of $5.8( \pm 1.75), 12.4( \pm 1.50)$ and $11.9( \pm 2.63)$ $\mathrm{mol} \cdot \mathrm{m}^{-2} \cdot \mathrm{d}^{-1}$, respectively. An average photoperiod was $10.5 \mathrm{~h}$ in the NSL treatment and $24 \mathrm{~h}$ in the PSL and WSL treatments.

Solution temperature treatments included supplying either heated or unheated nutrient solution to the roots under suboptimal air temperature conditions in the greenhouse. Electric heaters (200 W FS-218; Freesea, Guang Zhou, China) were used to increase the temperature of the nutrient solution. The heaters were set to maintain $20^{\circ} \mathrm{C}$ and placed at the bottom of the reservoirs. The unheated treatment did not contain heaters in the reservoir. The solution temperature in the unheated treatment was close to that of the ambient air. A temperature sensor (ST 110; Apogee Instruments) connected to a datalogger (CR1000x; Campbell Scientific) was placed in each reservoir to continuously there were 1536 plants ( 4 replications $\times 3$ light treatments $\times 2$ solution temperature treatments $\times 2$ PS $\times 8$ cultivars $\times 4$ plants per cultivar) grown in the study. An experimental unit contained four plants belonging to a cultivar within a PS subjected to a solution temperature treatment under a given light treatment in a replication.

Measurements and analyses. Environmental variables including DLI and air temperature were measured in the three light treatments and four replications using sensors placed at the canopy height and in the middle of each unit. Solution temperature and EC were measured in both the heated and unheated treatments belonging to the three light treatments. Solution temperature was measured in four replications, while solution EC was measured in three replications. The datalogger collected sensor data at hourly intervals and values were averaged for each day during the study. At harvest (the 40th day), collective shoot fresh weight of plants in each experimental unit was measured. Harvested plants from each experimental unit were placed in separate paper bags. They were dried in a forced-air oven maintained at $80{ }^{\circ} \mathrm{C}$ for seven days. The dried materials were weighed to measure collective shoot dry weight. Average fresh and dry weight of plants were determined by dividing the collective fresh and dry weights by total number of plants in each experimental unit (2-4). Average fresh and dry weights were multiplied with the number of plants $/ \mathrm{m}^{2}(\mathrm{NFT}=$ $44, \mathrm{CFT}=42$ ) to calculate SFW and SDW $\left(\mathrm{g} \cdot \mathrm{m}^{-2}\right)$. From this, SWC $(\%)$ was calculated as follows:

$$
\mathrm{SWC}=\frac{\mathrm{SFW}-\mathrm{SDW}}{\mathrm{SFW}} \times 100 .
$$

Data were analyzed according to a splitplot model using a "Proc Mixed" procedure of statistical analysis software (SAS, version 9.1; SAS Institute, Cary, NC). Least square means were separated using Tukey's honestly significant difference (HSD) procedure, with $P \leq 0.05$ considered statistically significant.

\section{Results and Discussion}

were Red Sails (Rs; red leaf) and Black Seeded Simpson (Bs; green leaf), belonging to the leaf lettuce group; Alkindus (Al; red leaf) and Adriana (Ad; green leaf), belonging to the butterhead group; Navara (Nv; red leaf) and Cedar (Ce; green leaf), belonging to the oak leaf group; and Breen $(\mathrm{Br}$; red leaf) and Salvius (Sa; green leaf), belonging to the romaine group.

Experimental design. The study was set up as a split-plot design with four replications of the whole-plot $(N=384)$. Replications were arranged perpendicular to the air temperature gradient inside the greenhouse. Whole- and subplots were randomly allotted in each replication. Whole plots included the three light treatments. The two solution temperature treatments were nested within each light treatment. Further, each solution temperature treatment used the two PS, and each PS unit supported eight cultivars. Altogether,
Growth environment. The EC of the solution supplied to the reservoirs varied on different days of the study to match nutrient supply with crop growth. On an average, nutrient solution EC ranged between 0.5 to $0.75 \mathrm{dS} \cdot \mathrm{m}^{-1}$ during the first $20 \mathrm{~d}, 0.75$ to 1.0 $\mathrm{dS} \cdot \mathrm{m}^{-1}$ between 21 and $30 \mathrm{~d}$, and 1.0 to 2.0 $\mathrm{dS} \cdot \mathrm{m}^{-1}$ between 31 and $40 \mathrm{~d}$ from the start (Fig. 2A). Solution EC increased rapidly above $2.0 \mathrm{dS} \cdot \mathrm{m}^{-1}$ on the 35 th day after transplanting (DAT), likely due to excess evaporation from the reservoirs. Plain water was added to the reservoirs on the 35th DAT to lower the nutrient solution EC. Averaged over the study period, plants received a nutrient solution with an EC of $0.98( \pm 0.229)$ $\mathrm{dS} \cdot \mathrm{m}^{-1}$. As expected, the average DLI received from sunlight was lower than optimal for lettuce $\left(12-15 \mathrm{~mol} \cdot \mathrm{m}^{-2} \cdot \mathrm{d}^{-1}\right)$ (Both et al., 

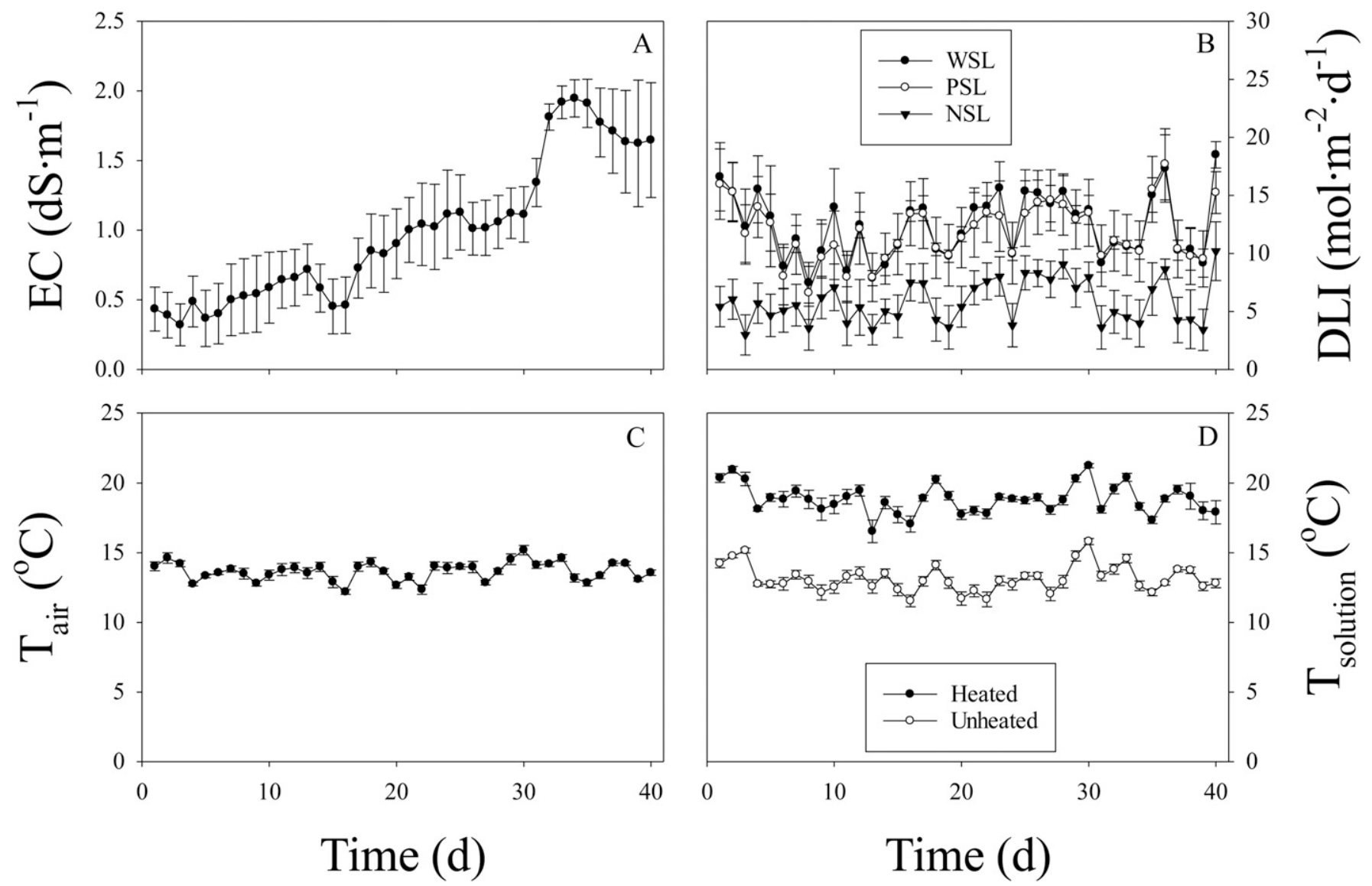

Fig. 2. Average electrical conductivity (EC) of the nutrient solution (A). Daily light integral (DLI) in the sunlight + narrow-spectrum supplemental light at nighttime (PSL), sunlight + full-spectrum supplemental light at nighttime (WSL), and sunlight without supplemental light (NSL) treatments (B). Air temperature $\left(\mathrm{T}_{\text {air }}\right)$ of the greenhouse $(\mathbf{C})$. Nutrient solution temperature $\left(\mathrm{T}_{\text {solution }}\right)$ in the heated $\left(18.8^{\circ} \mathrm{C}\right)$ and the unheated $\left(13.2^{\circ} \mathrm{C}\right)$ treatments, from the start of the experiment to harvest (D). Least square means and standard error of the mean (error bars) are shown.

1997; Kang et al., 2013; Zhang et al., 2018) and varied between 3.0 and $10.2 \mathrm{~mol} \cdot \mathrm{m}^{-2} \cdot \mathrm{d}^{-1}$ during the study (Fig. 2B). Light intensity received from SL at nighttime was consistent on different days and added an average of 6.56 and $6.04 \mathrm{~mol} \cdot \mathrm{m}^{-2} \cdot \mathrm{d}^{-1}$ in the WSL and PSL treatments, respectively (Fig. 2B). However, DLI also varied in the WSL and PSL treatments due to differences in sunlight intensity on different days. Daily average air temperature varied between 12.2 and $15.2{ }^{\circ} \mathrm{C}$ (Fig. $2 \mathrm{C}$ ) and was well below the optimal temperature of 20 to $24^{\circ} \mathrm{C}$ for lettuce (Brechner and Both, 2013; Gent, 2016). As the reservoir lids were not completely airtight, solution temperature in both the heated and unheated treatments varied on different days due to the changes in the greenhouse air temperature (Fig. 2D). Nutrient solution temperature ranged between 16.5 to $21.3^{\circ} \mathrm{C}$ in the heated treatment and 11.6 to $15.8{ }^{\circ} \mathrm{C}$ in the unheated treatment. However, the temperature difference between the heated and unheated treatments was consistent on different days (Fig. 2D).

Shoot dry weight. The observed statistical differences were identical for SFW and SDW measurements. The interaction between light and solution temperature treatments on SDW of lettuce was significant (Table 1, Fig. 3). This indicates that the light treatment effects on SDW were different in the heated and unheated solution treatments. Shoot dry

Table 1. Results of fixed effects analyses using 'Mixed' procedure of statistical analysis software (SAS). The experiment was set up in a split-plot design with three levels of subplots. Shown are different error terms used to test the main and interaction effects of whole-plot and subplots; effects; effect categories; degrees of freedom (df) for effects; and $P$ values for shoot dry weight (SDW) and shoot water content (SWC) measurements.

\begin{tabular}{|c|c|c|c|c|c|c|}
\hline$\overline{\text { Level }}$ & Error term & Effect & Effect category & $\overline{d f}$ & $P$ value (SDW) & $P$ value (SWC) \\
\hline & & $\mathrm{L} \times \mathrm{ST}$ & Two-way interaction & 2 & 0.0151 & $<0.0001$ \\
\hline \multirow{3}{*}{ Second subplot effects } & $\mathrm{R} \times \mathrm{L} \times \mathrm{ST} \times \mathrm{PS}$ & PS & Main & 1 & $<0.0001$ & 0.0002 \\
\hline & & $\mathrm{ST} \times \mathrm{PS}$ & Two-way interaction & 1 & 0.0372 & 0.0005 \\
\hline & & $\mathrm{L} \times \mathrm{ST} \times \mathrm{PS}$ & Three-way interaction & 2 & 0.1461 & 0.4785 \\
\hline \multirow[t]{6}{*}{ Third subplot effects } & $\mathrm{R} \times \mathrm{L} \times \mathrm{ST} \times \mathrm{PS} \times \mathrm{V}$ & $\mathrm{V}$ & Main & 7 & $<0.0001$ & 0.0141 \\
\hline & & $\mathrm{L} \times \mathrm{ST} \times \mathrm{V}$ & Three-way interaction & 14 & 0.2573 & 0.8028 \\
\hline & & $\mathrm{PS} \times \mathrm{V}$ & Two-way interaction & 7 & 0.0316 & 0.4811 \\
\hline & & $\mathrm{L} \times \mathrm{PS} \times \mathrm{V}$ & Three-way interaction & 14 & 0.1332 & 0.6743 \\
\hline & & $\mathrm{ST} \times \mathrm{PS} \times \mathrm{V}$ & Three-way interaction & 7 & 0.9314 & 0.6061 \\
\hline & & $\mathrm{L} \times \mathrm{ST} \times \mathrm{PS} \times \mathrm{V}$ & Four-way interaction & 14 & 0.8533 & 0.5839 \\
\hline
\end{tabular}

$\mathrm{R}=$ replication; $\mathrm{L}=$ light $\mathrm{ST}=$ solution temperature; $\mathrm{PS}=$ production system; $\mathrm{V}=$ variety. 
weight was highest in the PSL, followed by the WSL, and lowest in the NSL treatment, when heated solution was supplied to the plants. There were no differences in SDW between the PSL and WSL, and both had higher SDW than the NSL treatment when the unheated solution was supplied to the plants. Recently Kong et al. (2019) reported that LED fixtures with a higher proportion of red light and a red-to-blue ratio of $\approx 4.5$ resulted in maximum growth of lettuce cultivars in indoor production. This was attributed to increased photosynthetic efficiency under the high proportion of red light. Other studies indicated that a higher proportion of blue light $(>15 \%$ of total) reduced vegetative growth of lettuce (Zhang et al., 2018), likely due to higher-than-optimal energy from blue radiation. The PSL $\left(\mathrm{R}_{90}: \mathrm{G}_{0}: \mathrm{B}_{10}\right)$ and WSL $\left(R_{35}: G_{42}: B_{23}\right)$ fixtures used in our study differed largely in the proportion of red and blue light composition. Although sunlight received during the daytime contained a high proportion of blue relative to red light, the spectral composition of SL provided at nighttime contained a higher proportion of red and a lower proportion of blue in the PSL than in the WSL treatment (Fig. 1). This likely resulted in increased SDW in the PSL than WSL treatment, when the heated solution was supplied to the plants. Further, these results indicate that differences in SL spectra provided at nighttime can significantly affect lettuce growth regardless of sunlight composition. In the NSL treatment, plants received nearly half $\left(5.8 \mathrm{~mol} \cdot \mathrm{m}^{-2} \cdot \mathrm{d}^{-1} ;\right.$ Fig. 1$)$ of the optimal DLI (12 to $15 \mathrm{~mol} \cdot \mathrm{m}^{-2} \cdot \mathrm{d}^{-1}$ ) recommended for lettuce (Both et al., 1997; Kang et al., 2013; Zhang et al., 2018). Moreover, the spectral composition of sunlight with a higher proportion of blue could have further affected lettuce growth. These differences likely resulted in the lowest SDWregardless of solution temperature - in the NSL treatment.

The positive effects of heated nutrient solution on lettuce growth was previously reported (Kawasaki et al., 2014; Sakamoto and Suzuki, 2015; Thompson et al., 1998). Root temperature affected many aspects of lettuce growth, including morphology, respiration, transpiration, water movement, and nutrient uptake (Gent, 2016). Warm nutrient solution increased root growth, nutrient uptake, and air temperature of the surrounding plants (Kawasaki et al., 2014). Because of this, overall lettuce growth was likely higher in the heated compared with the unheated solution treatment (Fig. 3). The beneficial effects of optimal light composition in the PSL were likely absent in the unheated solution treatment and resulted in no differences between the two SL treatments. Further, it is interesting to note that the positive effects of heated solution on plants were not seen in the absence of SL (i.e., in the NSL treatment); whereas positive effects of SL on plant growth were present in the PSL and WSL treatment, even in the unheated solution treatment (Fig. 3). These results indicate that SL is most effective when light composition

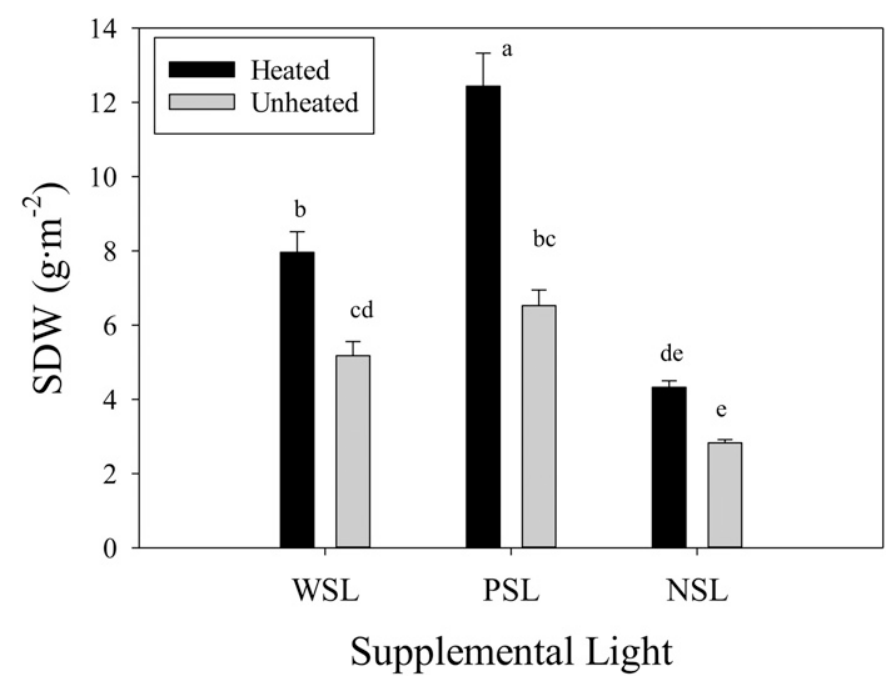

Fig. 3. Two-way interaction between light $(\mathrm{WSL}=$ sunlight + full-spectrum supplemental light at nighttime, PSL $=$ sunlight + narrow-spectrum supplemental light at nighttime, $\mathrm{NSL}=$ sunlight without supplemental light) and nutrient solution temperature [heated $\left(18.8^{\circ} \mathrm{C}\right)$ and unheated $\left.\left(13.2^{\circ} \mathrm{C}\right)\right]$ on lettuce shoot dry weight (SDW). Bars and error bars represent interactive least square means and standard error of mean, respectively. Means with different letters are significantly different $(P \leq 0.05)$.

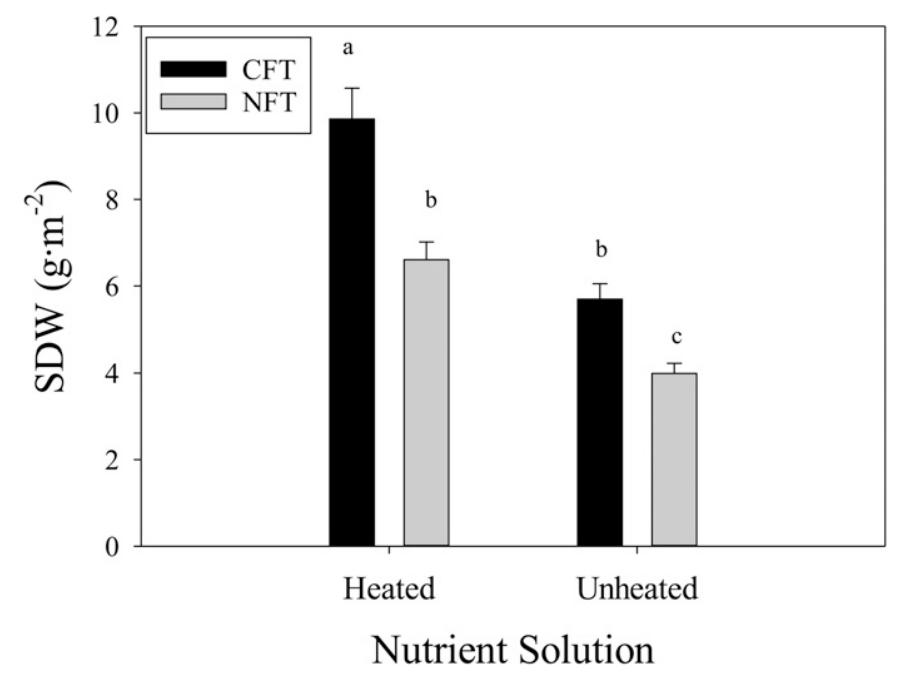

Fig. 4. Two-way interaction between nutrient solution temperature [heated $\left(18.8^{\circ} \mathrm{C}\right)$ and unheated $\left.\left(13.2^{\circ} \mathrm{C}\right)\right]$ and production system $(\mathrm{CFT}=$ constant flood table, NFT $=$ nutrient film technique) on lettuce shoot dry weight (SDW). Bars and error bars represent interactive least square means and standard error of mean, respectively. Means with different letters are significantly different $(P \leq 0.05)$.

is optimized (i.e., a higher proportion of red and a lower proportion of blue in the total light) and when roots are supplied with heated solution under suboptimal air temperature conditions. Supplying heated solution alone without adding SL may not have significant positive effects, whereas addition of SL without heated solution may increase lettuce growth.

There was a significant interaction between solution temperature and PS treatments on SDW of lettuce (Table 1, Fig. 4). This indicates that the effects of solution temperature on SDW were different in the CFT and NFT systems. Averaged across the light treatments and cultivars, SDW increase between the heated and unheated solution treatments was higher in the CFT than NFT system. The positive effects of heated solution were likely more pronounced in the CFT than NFT because roots grew completely inside the heated nutrient solution in the CFT, while a portion of roots were in contact with the heated nutrient solution in the NFT. Interestingly, SDW was higher in the CFT than NFT, even in the unheated solution treatment (Fig. 4). This may suggest additional advantages of growing plants (e.g., increased nutrient availability) in the CFT than NFT system. Our results indicate that increasing heated nutrient solution is most effective in hydroponics when roots are completely submerged in the solution, compared with those setups where roots are partially in contact with the nutrient solution. 
Table 2. Interactive effects of light treatment and cultivar, solution temperature and cultivar, and production system and cultivar on shoot dry weight of lettuce $\left(\mathrm{g} \cdot \mathrm{m}^{-2}\right)$. Interactive least square means with standard error of the mean in parentheses are shown.

\begin{tabular}{|c|c|c|c|c|c|c|c|c|c|}
\hline \multirow[b]{2}{*}{ Group } & \multirow[b]{2}{*}{ Color } & \multirow[b]{2}{*}{ Cultivar ${ }^{z}$} & \multicolumn{3}{|c|}{ Light treatment ${ }^{\mathrm{y}}$} & \multicolumn{2}{|c|}{ Solution temperature $\mathrm{x}$} & \multicolumn{2}{|c|}{ Production system ${ }^{w}$} \\
\hline & & & WSL & $\begin{array}{l}\text { PSL } \\
\end{array}$ & NSL & Heated & Unheated & CFT & NFT \\
\hline$\overline{\text { Leaf }}$ & Red & Rs & $6.6(0.96) b-g$ & $11.3(1.60) \mathrm{a}$ & $(0.42)$ & $9.6(1.25) \mathrm{ab}$ & 5.1( & $8.7(1.28) a b c$ & $6.0(0.77) \mathrm{cd}$ \\
\hline Oak Leaf & Green & $\mathrm{Ce}$ & $5(0.81) a-d$ & $11.4(1.55) \mathrm{a}$ & $3.8(0.31) \mathrm{d}-\mathrm{g}$ & $9.3(1.23) \mathrm{abc}$ & $5.8(0$ & $8.6(1.26) a b c$ & $6.4(0.72) \mathrm{bcd}$ \\
\hline \multirow[t]{2}{*}{ Butterhead } & Green & $\mathrm{Ad}$ & $6(1.33) \mathrm{abc}$ & $10.7(1.74) a b$ & $3.9(0.36) \mathrm{d}-\mathrm{g}$ & $10.3(1.34) \mathrm{a}$ & $5.2(0.70) \mathrm{de}$ & $9.3(1.36) \mathrm{ab}$ & $6.2(0.89) \mathrm{bcd}$ \\
\hline & Red & $\mathrm{Al}$ & $5.5(0.67) \mathrm{c}-\mathrm{g}$ & $6.8(0.92) b-g$ & $3.3(0.23) \mathrm{d}-\mathrm{g}$ & $6.2(0.69) \mathrm{cde}$ & $4.2(0.45)$ de & $6.5(0.72) \mathrm{bcd}$ & $3.9(0.32) d$ \\
\hline Romaine & Green & $\mathrm{Sa}$ & $8.7(1.23)$ abc & $11.4(1.84) \mathrm{a}$ & $4.1(0.42) \mathrm{d}-\mathrm{g}$ & $10.2(1.41) \mathrm{a}$ & $5.9(0.79)$ de & $10.2(1.45) \mathrm{a}$ & $5.9(0.69) \mathrm{cd}$ \\
\hline
\end{tabular}

${ }^{\mathrm{z}}$ Adriana (Ad), Alkindus (Al), Black Seeded Simpson (Bs), Breen (Br), Cedar (Ce), Navara (Nv), Red Sails (Rs), and Salvius (Sa).

${ }^{\mathrm{y}} \mathrm{WSL}=$ sunlight + full-spectrum supplemental light at nighttime; PSL $=$ sunlight + narrow-spectrum supplemental light at nighttime; NSL $=$ sunlight without supplemental light.

${ }^{\mathrm{x}}$ Heated $\left(18.8^{\circ} \mathrm{C}\right)$ and unheated $\left(13.2^{\circ} \mathrm{C}\right)$.

${ }^{\mathrm{w}} \mathrm{CFT}=$ constant flood table; NFT $=$ nutrient film technique.

${ }^{\vee}$ Means followed by different letters were statistically different at $P \leq 0.05$. a-e indicates abcde.

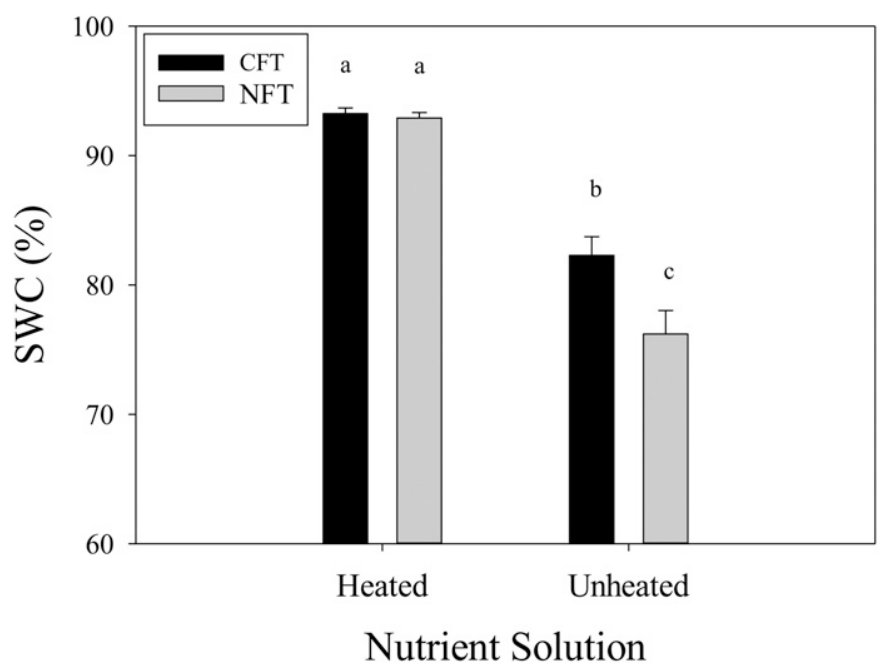

Fig. 5. Two-way interaction between nutrient solution temperature [heated $\left(18.8^{\circ} \mathrm{C}\right)$ and unheated $\left.\left(13.2^{\circ} \mathrm{C}\right)\right]$ and production system $(\mathrm{CFT}=$ constant flood table, NFT $=$ nutrient film technique $)$ on lettuce shoot water content (SWC). Bars and error bars represent interactive least square means and standard error of mean, respectively. Means with different letters are significantly different $(P \leq 0.05)$.

In addition, the interaction between the light and production system treatments on SDW was significant. Although SDW was higher in the PSL than the WSL or NSL, the increases in SDW observed under PSL were higher in the CFT than NFT. The SDW in the PSL treatment was higher than the WSL treatment by $47 \%$ and $42 \%$ in the CFT and NFT systems, respectively. The SDW difference between PSL and NSL was $228 \%$ in the CFT and $51 \%$ in the NFT. These results indicate that, regardless of solution temperature, lettuce yields are higher in the PSL and CFT treatments.

The two-way interactions between the light and cultivar (Table 2A), the solution temperature and cultivar (Table 2B), and the PS and cultivar (Table 2C) treatments were significant for SDW. These interactions indicate that the effects of the light, the solution temperature, and the PS treatments on SDW varied among the cultivars. While SDW of cultivars generally trended higher in the PSL than WSL, it was significantly higher in the PSL for Red Sails (leaf lettuce, red color;
Table 2A). Although SL increased SDW in all cultivars, there were no differences among the three light treatments in Breen cultivar (romaine lettuce with a red leaf color). Shoot dry weight was generally higher among cultivars in the heated compared with unheated treatment (Table 2B). However, there were no differences in the SDW of 'Navara', 'Alkindus', and 'Breen' between the heated and unheated solution treatments. These cultivars belong to oakleaf, butterhead, and romaine groups, respectively, with red leaves. Shoot dry weight of cultivars trended higher in the CFT than NFT, and it was significantly higher in the CFT for Salvius (leaf lettuce, green color; Table 2C). These results indicate that differences among the cultivars were generally minimal for any effect. This is likely because the cultivars were selected based on their best performance in a preliminary trial. However, some cultivars responded selectively to the solution temperature treatment. The positive effects of the heated solution on plant growth were not observed in three out of four red leaf color cultivars in our study and present in all green leaf color cultivars. Our results also suggest that SDW is generally higher in cultivars belonging to the leaf lettuce group than other groups and those with green than red leaf color.

Shoot water content. The interaction between the solution temperature and PS treatments was significant for SWC (Table 1, Fig. 5). This indicates that SWC differences between the heated and unheated solution temperature treatments were different in the CFT and the NFT systems. The SWC of both PS was higher in the heated than the unheated treatment. The increase in SWC between the heated and the unheated treatments was more in the CFT than in the NFT system (Fig. 5). Previously, several studies reported increased root growth using a heated hydroponic solution (Kawasaki et al., 2014; Thompson et al., 1998). Root growth was not measured in the present study. However, we observed larger root systems in the heated than unheated solution treatment. Increased root growth likely increased water uptake and overall growth in the heated compared with the unheated solution treatment. Effects of using heated nutrient solution on SWC were more pronounced in the CFT than NFT, likely due to complete submergence of roots in the CFT. This likely increased root growth and water uptake in the CFT than NFT. There was a significant interaction between the light and solution temperature treatments on SWC. However, the observed interactive effects were like those described for the interaction between the light and solution temperature treatments on SDW. This is likely because both SWC is a major component of SFW, and further SDW and SFW responded similarly to treatments. Among the cultivars, Breen had significantly lower SWC than Cedar, Red Sails, and Salvius. Shoot dry weight of Breen did not respond to SL (Table 2A). Economic yield in lettuce is proportional to fresh weight, which is mostly comprised of water. Our results indicate that higher levels of SWC, thereby higher economic yields, can be achieved using the heated nutrient solution or the CFT production system during winter production. 


\section{Conclusions}

In this study, we investigated the interaction among nighttime SL composition, solution temperature, PS, and cultivar treatments on lettuce productivity when suboptimal air temperature was maintained in the greenhouse similar to winter conditions in the northern regions of the United States. Our results indicate that lettuce productivity is affected by the interaction among different environmental- and production-related factors. Supplemental lighting provided at nighttime effectively increased lettuce growth. Further, our results indicate that nighttime SL composition can be optimized to maximize lettuce yield in greenhouses. Maximum lettuce growth was observed when SL containing a higher proportion of red and a lower proportion of blue light (i.e., PSL), along with a heated nutrient solution $\left(18.8^{\circ} \mathrm{C}\right)$, was provided to plants when suboptimal temperatures were maintained in the greenhouse. Our results recommend that growers provide SL while using heated solution. Without the addition of SL, there were no significant positive effects of heated solution on plant growth. Results from this study demonstrate that the responses of lettuce growth and shoot water content (a major component of economic yield) to heated solution were higher in the CFT than NFT system. This is likely due to a complete submergence of roots in the warmer nutrient solution, in the CFT system. However, the positive effects of heated solution on plant growth were absent in many red leaf lettuce cultivars used in our study. Growers can use the information generated from this study to make informed decisions about their investment. Further, the information can be used to maximize hydroponic lettuce productivity and increase profits during winter production in greenhouses.

\section{Literature Cited}

Aldrich, R.A. and J.W. Bartok. 1989. The northeast regional agricultural engineering service, p. 212. In: M. Sailus, C. Napierala, and M. Sanders (eds.). Greenhouse engineering. 3rd ed. Ithaca, NY.

Assimakopoulou, A., A. Kotsiras, and K. Nifakos. 2013. Incidence of lettuce tipburn as related to hydroponic system and cultivar. J. Plant Nutr. 36:1383-1400.

Both, A., L. Albright, R. Langhans, R. Reiser, and B. Vinzant. 1997. Hydroponic lettuce production influenced by integrated supplemental light levels in a controlled environment agriculture facility: Experimental results. Acta Hort. 418:45-52.

Brechner, M. and A.J. Both. 2013. Hydroponic lettuce handbook. Cornell Controlled Environmental Agriculture. 30 May 2020. $<$ https://cpbus-e1.wpmucdn.com/blogs.cornell.edu/dist/8/ 8824/files/2019/06/Cornell-CEA-Lettuce-Handbookpdf 5 .

Brumfield, R. 2007. Dealing with rising energy costs. 30 May 2020. <https://gpnmag.com/ article/dealing-rising-energy-costs/>.

Curran, J. 2018. Hydroponic crop farming. IBIS World. 30 May 2020. <https://my.ibisworld.com/us/en/industry-specialized/od4012/products-and-markets $>$.

Dufault, R.J., B. Ward, and R.L. Hassell. 2009. Dynamic relationships between field temperatures and romaine lettuce yield and head quality. Scientia Hort. 120:452-459.

Gent, M.P. 2014. Effect of daily light integral on composition of hydroponic lettuce. HortScience 49:173-179.

Gent, M. 2016. Effect of temperature on composition of hydroponic lettuce. Acta Hort. 1123:95-100.

Gerovac, J.R. and R.G. Lopez. 2014. Bench-top root zone heating: Can you reduce air temperatures and finish bedding plants on time? Greenhouse Grower. 30 May 2020. <https://www.greenhousegrower.com/technology/bench-top-root-zoneheating-can-you-reduce-air-temperatures-and-finishbedding-plants-on-time $/>$.

Grahn, C.M., B. Hellier, C. Benedict, and C. Miles. 2015. Screening USDA lettuce (Lactuca sativa L.) germplasm for ability to germinate under cold conditions. HortScience 50:1155-1159.

Ikeda, H., T. Wada, T. Mirin, K. Okabe, A. Tazuke, and H. Furukawa. 1995. Year-round production of spinach by NFT and DFT in the greenhouse. Acta Hort. 396:257-264.

Jensen, M.H. 1999. Hydroponics worldwide. Acta Hort. 481:719-730.

Kang, J.H., S. Krishnakumar, S.L. Atulba, B.R. Jeong, and S.J. Hwang. 2013. Light intensity and photoperiod influence the growth and development of hydroponically grown leaf lettuce in a closed-type plant factory system. Hort. Environ. Biotechnol. 54:501-509.

Kawasaki, Y., S. Matsuo, Y. Kanayama, and K. Kanahama. 2014. Effect of root-zone heating on root growth and activity, nutrient uptake, and fruit yield of tomato at low air temperatures. J. Jpn. Soc. Hort. Sci. 83:295-301.

Kong, Y., A. Nemali, C. Mitchell, and K. Nemali. 2019. Spectral quality of light can affect energy consumption and energy-use efficiency of electrical lighting in indoor lettuce farming. HortScience 54:865-872.

Korczynski, P.C., J. Logan, and J.E. Faust. 2002. Mapping monthly distribution of daily light integrals across the contiguous United States. HortTechnology 12:12-16.

Lennard, W.A. and B.V. Leonard. 2006. A comparison of three different hydroponic subsystems (gravel bed, floating and nutrient film technique) in an aquaponic test system. Aquacult. Intl. 14:539-550.

Marsh, L.S. and S. Singh. 1994. Economics of greenhouse heating with a mine air-assisted heat pump. Trans. ASAE 37:1959-1963.

Nelson, J.A. and B. Bugbee. 2014. Economic analysis of greenhouse lighting: Light emitting diodes vs. high intensity discharge fixtures. PLoS One 9(6): e99010.

Ouzounis, T., E. Rosenqvist, and C.-O. Ottosen. 2015. Spectral effects of artificial light on plant physiology and secondary metabolism: A review. HortScience 50:1128-1135.

Sakamoto, M. and T. Suzuki. 2015. Effect of root-zone temperature on growth and quality of hydroponically grown red leaf lettuce (Lactuca sativa L. cv. Red Wave). Amer. J. Plant Sci. 6:2350-2360.

Tewolde, F.T., N. Lu, K. Shiina, T. Maruo, M. Takagaki, T. Kozai, and W. Yamori. 2016. Nighttime supplemental LED inter-lighting improves growth and yield of single-truss tomatoes by enhancing photosynthesis in both winter and summer. Frontiers Plant Sci. 7:448.

Thompson, H.C., R.W. Langhans, A.J. Both, and L.D. Albright. 1998. Shoot and root temperature effects on lettuce growth in a floating hydroponic system. J. Amer. Soc. Hort. Sci. 123:361-364

National Centers for Environmental Information (NCEI). 2020. U.S. climate atlas. 30 May 2020. $<$ https://www.ncdc.noaa.gov/climateatlas/>.

Walters, K.J. and C.J. Currey. 2015. Hydroponic greenhouse basil production: Comparing systems and cultivars. HortTechnology 25:645650.

Zhang, X., D . He, G. Niu, Z. Yan, and J. Song. 2018. Effects of environment lighting on the growth, photosynthesis, and quality of hydroponic lettuce in a plant factory. Intl. J. Agr. Biol. Eng. 11:33-40 